\section{Military Technical College Cairo, Egypt}

\author{
$12^{\text {th }}$ International Conference \\ on Applied Mechanics and \\ Mechanical Engineering (AMME)
}

\title{
A SAFETY PLAN FOR AN INDUSTRIAL PLANT
}

\author{
Ramadan, M.R., Mohamed, M.A.S. , Assar, A. and Risha H.A.
}

\begin{abstract}
Discussed is a comprehensive approach to assess environmental safety prior to the controversial decision as to whether an industrial plant to stay operative or shut down.

The study suggests that the plant be committed to present updated periodic records about its environment-damaging outputs. Such records are then analyzed based on Statistical Process Control charts.

A sound safety control is realized via a routine report analysis, followed by appropriately enforced measures. The Control Charts adjust plant safety continuously by comparison with the allowable limits and set the control limits for expected future performance. In addition, three levels of imposed enforcements are involved at safety plan and recommended; being respective penalty fines, temporary halt for a limited-scale correction, and long shut down for an overhaul.
\end{abstract}

\section{KEYWORDS}

Statistical Process Control, Safety Control, Environmental Damages, Automobile Assembly Plants. 


\section{INTRODUCTION}

An industrial plant is solely built to manufacture a useful product for man or other environmental entities. Owing to the closed feature of the environmental system, both the plant and its products often have parallel adverse effects. Thus, the mere environmental gain achieved by an introduced product should be balanced to the sum of its direct negative effect along with the natural damage due to its manufacturing plant [1-3]. The detrimental effect of a prospective product can be restricted based on Statistical Process Control (SPC) charts [4-7].

Government-backed inspectors used to follow systematic approaches to assess plant safety. Conventional approaches include periodic routine inspections, testing of a random sample, and unexpected unique visits. However, literature shows a few conservative attempts to deal with the plant safety based on a standard approach of SPC [8-9].

This paper puts forth a methodological approach to fairly deal with the question of environmental safety of industrial plants. It is intended to reduce the unsettled debates and conflicts between environment-protection supporters and industryexpansion supporters. The study adopts a fact that establishment of a new industry involves a tacit approval of a limited sacrifice of a type of environmental resources. For each prospective plant, the allowable sacrifice includes common and specific features. The plant developer will be committed to monitor the plant harms by continuous recording. Based on the analysis of such records, a fair and satisfactory measure is immediately taken depending on the level of safety violation. The suggested approach is presented in the form of a case study handling the safety of an automobile plant.

\section{ENVIRONMENTAL DAMAGES DUE TO A PLANT}

The structure and processes of a plant are presumably in a continuous need of requirements to be drained mainly from the environmental system, see Fig.(1). Even the plant normal activities negatively disturb the natural states and cycles of the environmental system. In other words, the plant emergence and stability will somehow incapacitate the environment but only within well calculated acceptable limits. These limits should then be respected since those early stages of the plant planning and construction, as well as during its routine operations. An automobile plant, like any type of industrial plants, will cause common and specific harms to the environmental system.

\subsection{Common Harmful Features}

All industrial plants entail common essential requirements that often disturb environmental balance. For instance, as viewed from its surrounding, any plant is a concentrated area full of gathered activities which disturb the natural distribution or self-balanced densities of the environmental system. Plant risks are augmented, assembled and accumulated to endanger and threaten people outside, who should be sometimes evacuated. Thus, there are some considerations to follow in order to accept a proposed industrial plant; namely, 
erection on uncultivated land, availability of the site ordinary needs such as accessibility roads, and being far away from residential areas.

On the other hand, viewed as a man-operated system, a plant is a highly disciplined space where an extra care should be taken. In other words, people inside any industrial plant face a constrained workplace with controlled human behaviors. Here man is required to move and work within a narrow area full of running and moving machinery.

\subsection{Specific Harmful Features}

An automobile's factory has its own specific constructions and layout plan, being designed for mass production and assembly lines. The factory is also full of a large number of automatic machinery with high-speed rotating parts. Heavy aggregates are hung using material handling equipment. Heat and chemical treatments entail high-temperature furnaces. Testing devices include fluid high pressure vessels. Man has to operate and move between such machineries, and thereby injury likelihood is often expected.

In addition, an automobile factory has distinctive processes to be done on raw materials and numerous machine parts. Trained labors and tight regulations have well distinguished aspects. For instance, in such factories we expect to find the welding, finishing and painting departments where these processes introduce foreign vapors to the factory atmospheric air. These regions and their air harmful outputs are shown in Fig.(2). Industrial wastes are treated to run to waterways, whereas concentrated scraps are buried in an unfavorable area.

These specific features call for extra human attention, routine inspection and maintenance. Otherwise, environmental damages may exceed allowable levels.

\section{THE ENVIRONMENTAL SAFETY OF A PLANT}

The article above assumes the planner's ability to exactly count all environmental requirements that a new plant facility needs for its proper existence, whether during the evolution stage or during normal operations. The next step is to specify which one of the six environmental entities is directly harmed. The third step is to appraise the net deficiency incurred by the entity. Based on the estimate of overall profit predicted from automobile industry, an equivalent level of a sacrificed ratio is allowed This is a question of a compromise, trade-off, and balancing of the industry turnover versus its environmental deficiencies.

Real records of damaging outputs, critical processes, and hazardous machinery always show a random behavior in the form of a time series. Thus, a preliminary safety test is to check the closeness of the moving average of the random records to the allowable level of environmental damages. The second test is to apply the Statistical Process Control to calculate the Upper and Lower Control Limits that the sample submean records should not go beyond. The control charts are checked for both the moving average and range. 


\section{RECORDS OF AN AUTOMOBILE PLANT}

\subsection{Effect on Man}

The proposed method is now applied to an industrial plant for automobiles to be assembled from about 100 semi-finished and finished components. These components are manufactured by means of some 8000 to 10000 minor parts. Our investigation surveys the incident records of labor injuries and casualties in the year interval of 2000-2005. In addition, some of environment's related records are picked up at some productive regions of the plant for dangerous gases and particles, temperature rise, and wastewater contaminants. Randomly varying record values are so arranged as a time series that itsoverall mean value is a moving average of ten successive records. The principle is to use recent process performance data as a base to set the limits that control the expected future performance. Each future sample consists of only two records to estimate the submean and range of annual records.

Human injuries occurring in automobile plant are summarized in Figs.(3 and 4) which show a scheme of significant changes in the process by using control limits $(\overline{\mathbf{X}}-\mathbf{R})$ charts. Figs.(3 and 4$)$ show that the number of human injuries at all departments of plant is within control limits as the same indication for $\overline{\mathbf{X}}$ and $\mathbf{R}$ charts. Other relevant data handled the number of wasted days of disable injured persons well below UCL but the LCL itself is less than zero line because records for many injury-free minor accidents often go overlooked. Furthermore, the high number of human injuries is concentrated at such production departments as welding, assembly, and finishing processes.

\subsection{Effect on Air}

The effect of emission of serious gases on the plant air are recorded and monitored by using control limits ( $\overline{\mathbf{X}}-\mathbf{R}$ charts). Records are collected at five plant regions; being the furnaces, the painting, body assembly, service center, and final center.

The Total Suspended Particles (TSP) and temperature rise in the paint department are recorded and found to be within the control limits. Fig.(5) illustrates the submean sampled records and relevant limits.

The emissions records of Total Particle Matters (TPM), such as CO, NOx, HC, and $\mathrm{SO} 2$ in the furnaces area are then investigated. It is found that the concentration of TPM in the furnaces area is beyond UCL in 2002. On the other hand, the TPM is found within control limits in the year interval 2003-2005. In addition, emission of $\mathrm{CO}, \mathrm{NOx}$, and $\mathrm{HC}$ are often within control limits in the period 2002-2005. An exception is that SO2 is beyond UCL in 2002, other relevant records of SO2 in the period 2003-2005 are within the control limits.

The TSP, CO and $\mathrm{CO} 2$ emissions in the region of body assembly are also investigated. It is found that records are within the control limits except those of the CO emissions in 2002 where they go beyond UCL Fig.(6) shows a good example of the records for $\mathrm{CO} 2$ emissions. Although the four submean records are within control limit, cyclic behavior indicates the presence of unfavorable processes which require a temporary halt to pinpoint the causes. On the other hand, the computations of the LCL are found so sensitive to the accuracy of the 
data recorded which may cause the LCL to erroneously lie below zero level for TSP and CO.

Emission records of $\mathrm{CO}$ and $\mathrm{CO} 2$ in the services and final centers are thoroughly investigated as well. From Fig.(7), it is clear that the emissions of CD are within the control limits but with an unfavorable cyclic behavior.

Most of previous records are close to the allowable levels given by the environment law number (4), issued in 1994 in Egypt. However, four cases are observed where allowable levels are exceeded. These are the concentration of $\mathrm{CO}$ at welding region in 2002, the CO emission in the paint area in 2005, the concentration of TPM in one of the paint areas in the year interval 2003-2004, and also concentration of TPM at one of furnaces as shown in fig.(8) in year 2002 in spite of it's within the allowed limit $(200 \mathrm{mg} / \mathrm{m} 3)$.

It should be recalled that allowable safe levels are not standardized and are only used for comparison purposes of air pollution. They are considered as general guidelines adopted by some regions like WHO, EU standard which varies once every a number of years, East of Asia countries, and the Third World.

\subsection{Effect on Wastewater}

Industrial wastewater is treated and then drained at a final discharge, where recorded measurements are collected. Data are then analyzed using control limits $\overline{\mathbf{X}}$ - chart. Data encompass the concentration of TSS (total suspended solids), Oil and Grease, Total Nitrogen, copper ( $\mathrm{Cu}$ ) Cadmium (Cd) and Nickel (Ni). For instance, Figs.( 9 and 10) show that $\mathrm{Ph}$ and $\mathrm{Cd}$ are within the control limits. However the Cd concentration in 2005 is below LCL due to a probable record error.

\section{ANALSIS AND DISCUSSION}

In Fig.(1) we showed a sample of an injury control chart. The chart is based on real recorded data for recent five years which are approximately similar to the previous years. However, the calculated mean value $\overline{\mathbf{X}}$ should be close enough to a referenced allowable level. Besides, the control charts ( $\bar{x}$ and $R$ ) give the same indication ( within or exceed limits). Based on the nature of any facility, many safety professionals know for granted that the facility has a normal occurrence of human incidents, resulting in an annual allowable level of either injuries or casualties. This allowable level is expressed as an injury frequency rate, severity rate and severity average. The facilities' managers could claim that the injury-producing processes are in statistical control as long as the number of injuries remains close to the predicted allowable value.

However, researches that seek an injury allowable value are still controversial since the Information of occupational accidents is not standardized worldwide [10]. It is observed that the accidents reported to International Labor Organization (ILO) correspond to only $3.9 \%$ of the actual number of accidents worldwide. Although an exact number of actual accidents are significantly under-reported, reported data are still used as a baseline for occupational safety work in industry and other sectors. In addition, the reported accidents vary among different regions or even among different factories. For instance, the 
Established Market Economics (EME) region is found to report $62 \%$ of their occupational accidents to ILO, whereas India, the other Asia and Islands (OAI) region have modest reports close to $0 \%$. Also, it is likely that countries encompassed in the same region report various percentages of occupational human accidents [11].

We notice that heat is generated from different areas, such furnaces, welding processes, and painting. Similarly, $\mathrm{CO} 2$ is output from both assembly and service departments. Thus, for such cases, the $\mathrm{CO} 2$ emission and temperature rise are summed up to express the net damaging effect of the plant on air.

In assessing the plant safety, records carried out and presented by the plant's devices are questionable and should be reviewed by state-planned routine inspections using calibrated devices over a quite long period of time.

For those charts where records show cyclic behavior, Figs.(6 and 7), the plant should be temporary halted to search for the causes. Nevertheless, the allowed safe limits are not standard and are only used for comparison purpose. So, the Control Charts are able to take such preventive actions as will remove trouble making causes before risk items are produced. The research focuses on number of actions at master safety plan. This master plan is a part of basic safety plan. Furthermore, safety plan consists of number of items such as information, safety manual ( policy, instructions, and procedures ), training, motivation, and organization. Moreover, the plan proposes for any industrial plant three sets of quick remedial actions worth mentioning. First; replacement, repair and maintenance of machinery. Second; upgrading the technical and managerial processes. Third; labor training and updating the regulations

\section{CONCLUSION}

In addition to the profit drawn from a prospective product, there is always an inevitable equivalent harm incurred by the environmental system. This harm consists of two parts; being the harm of product and the harm of the manufacturing plant. The paper focuses solely on the harm of manufacturing plant. The objective is to outline a common safety criterion while planning and operating any industrial plant since its existence depends mainly on a type of continuous environmental interaction.

Harm of the manufacturing plant has general and particular features. The general features are common for whatever plant whether manufacturing light or heavy industrial products. For instances, any industrial plant encompasses automatic machinery in a concentrated area. The harm is thus concentrated against natural environment surrounding the local area. In addition, the human involved inside should behave carefully amongst machinery.

On the other hand, each specific industry has its particular features, such as distinguished machinery, processes, and scraps. For instance, a textile plant is noisy, lint-polluted, and die-sewage, whereas an automobile plant encompasses heavy machinery, heat furnaces, paints vapors, high pressure containers.

To monitor the accepted level of harm of an industrial plant to environmental system, the paper suggests continuous reporting of harm records subject to analysis via a Statistical Process Control. Violations of safety regulations are handled by three penalty levels. First, for each submean going beyond control limits, the plant should be charged respective penalty fines. Second, for such 
distinct deterministic behaviors as trends and cyclic records, the plant should be temporarily halted to pinpoint causal deficiencies. Third, if records follow a static pattern or are always beyond control limits, the plant should be immediately shut dowreither partially or fully .

\section{REFERENCES}

[1] Friedhelm Nachreiner, Peter Nickel, Inga Meyer. Human factors in process systems: The design of human-machine interfaces, Safety Science vol. 44, 2006, pp. 5-26.

[2] Elie Fadier, Cecillia De la Garza. Safety design: Towards a new philosophy, Safety Science, vol. 44, 2006, pp 55-73.

[3] Paivi Hamalainen, Jukka Takala, Kaija Leena Saarela. Global estimates of occupational accidents, Safety Science, Vol. 44, Issue2, February 2006, pp. $1-20$.

[4] Per Hokstad, Trygve Steiro. Overall strategy for evaluation and priority setting of risk regulations, Reliability Engineering and System, vol.91, 2006, pp.100-111

[5] X.cuny and M. Lejeune, Statistical modeling and risk assessment, Safety Science, Vol. 41, Issue 1, Feb. 2003, pp. 29-51.

[6] J.L. Rouvroye and E.G. Van dan Bliek, Comparing safety analysis techniques, Reliability Engineering \& System Safety, Vol. 75, 2002, pp. 289294

[7] A.Richei, U. Hauptmanns, H. Unger, The human error rate assessment and optimizing system HEROS- a new procedure for evaluating and optimizing the man-machine interface in PSA, Reliability Engineering \& System Safety Vol. 72, 2001, pp. 153-164.

[8] Hossam A. Gabbar, kazuhiko Suzuki, and Yukiyasu shimada, Design of plant safety model in plant enterprise engineering environment, Reliability Engineering \& System Safety, Vol. 73, 2001, pp. 35-47.

[9] R.W. Youngblood, Risk significance and safety significance, Reliability Engineering \& System Safety, Vol.73, 2001, pp. 121-136.

[10] T.P. Kelly, J.A. McDermid, A systematic approach to Safety case maintenance, Reliability Engineering \& System Safety, Vol. 71, 2001, pp. 271-284.

[11] S.J. Cox, and A.J.T. Cheyne, Assessing safety culture in offshore environments, Safety Science, Vol. 34, 2000, pp. 111-129. 


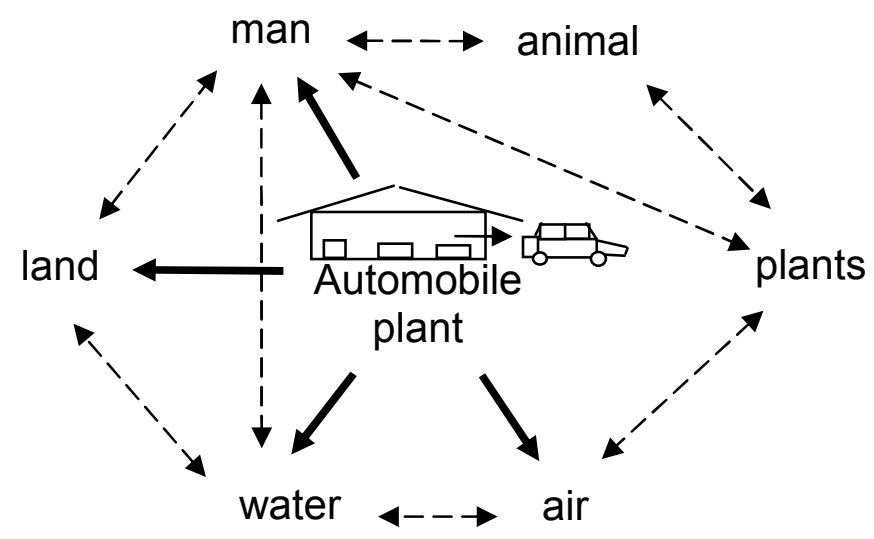

Fig.1 The Direct Harmful Effects of an Automobile Plant on the Environmental Entities
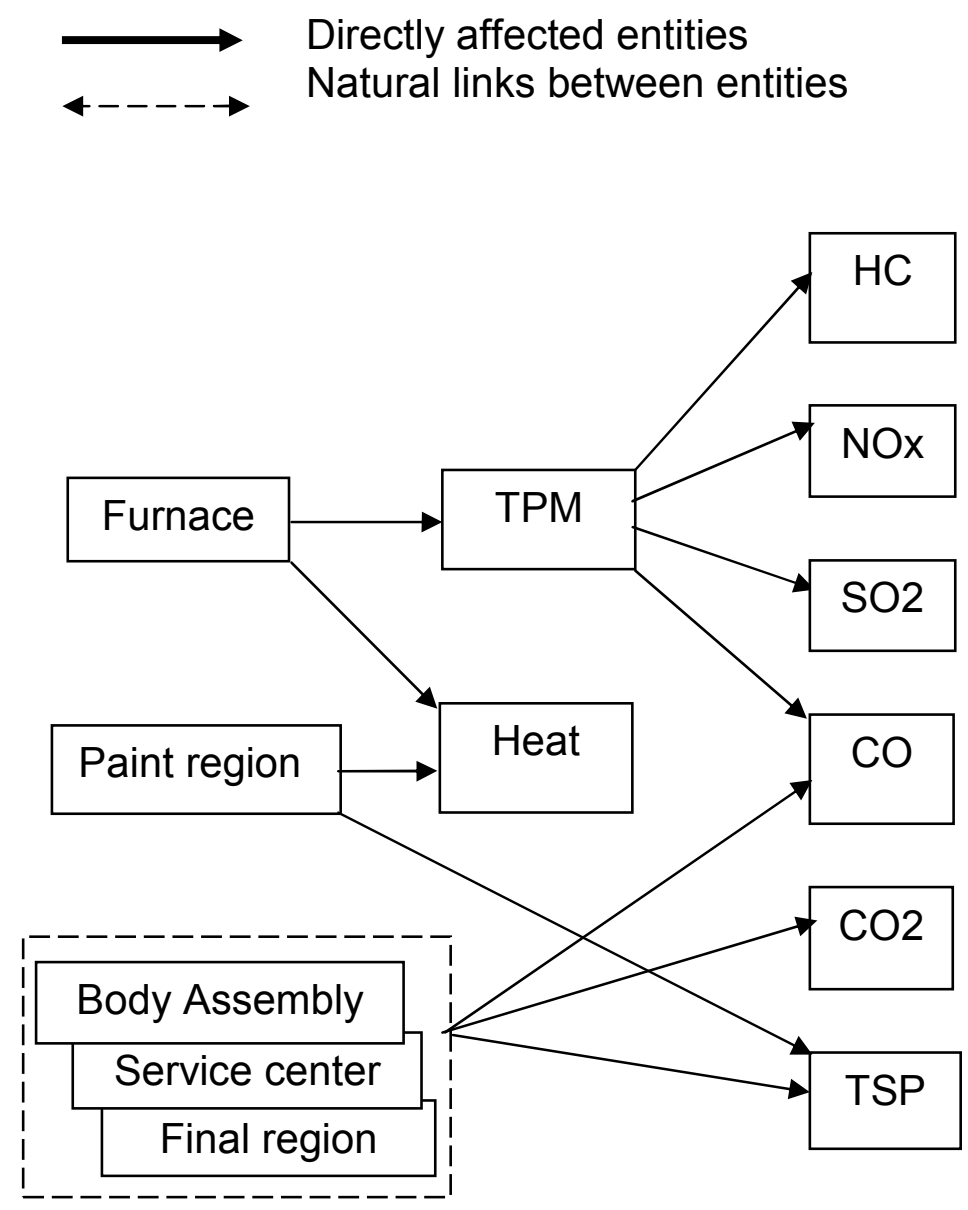

Fig.2 Departments Of An Automobile Plant And Their Detrimental Outputs To The Air 


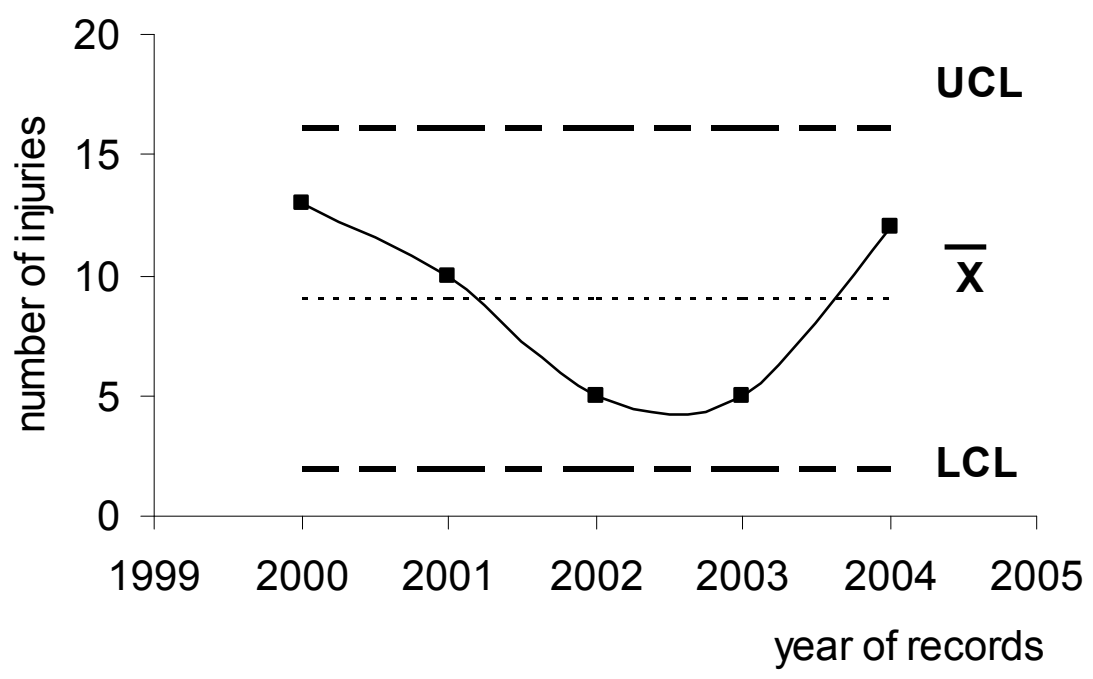

Fig(3) Number of injuries in an automobile plant

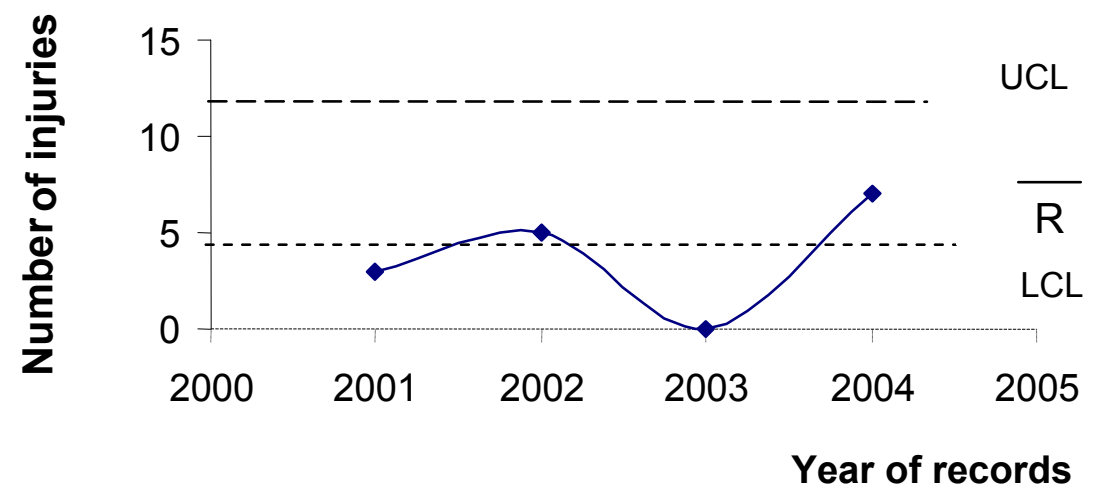

Fig. 4 Range of injuries in an automobile plant 


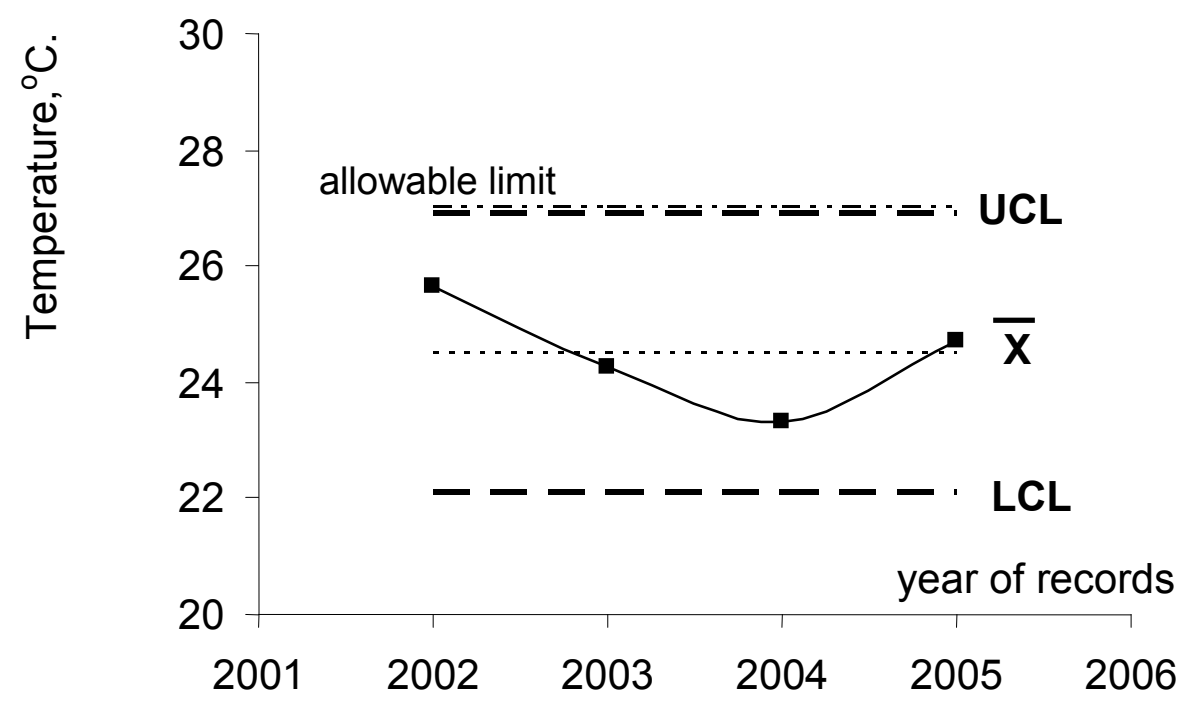

Fig.(5) Temperature rise in paint department

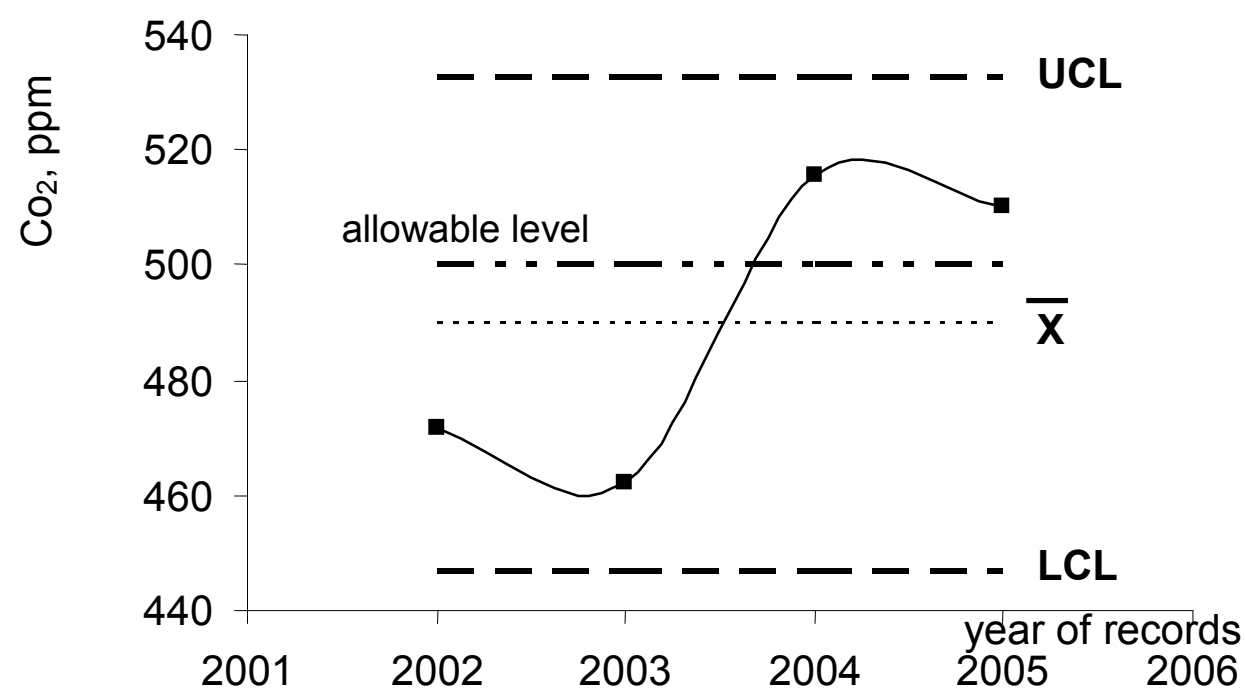

Fig.(6) $\mathrm{CO}_{2}$ Emission in body assembly Department 


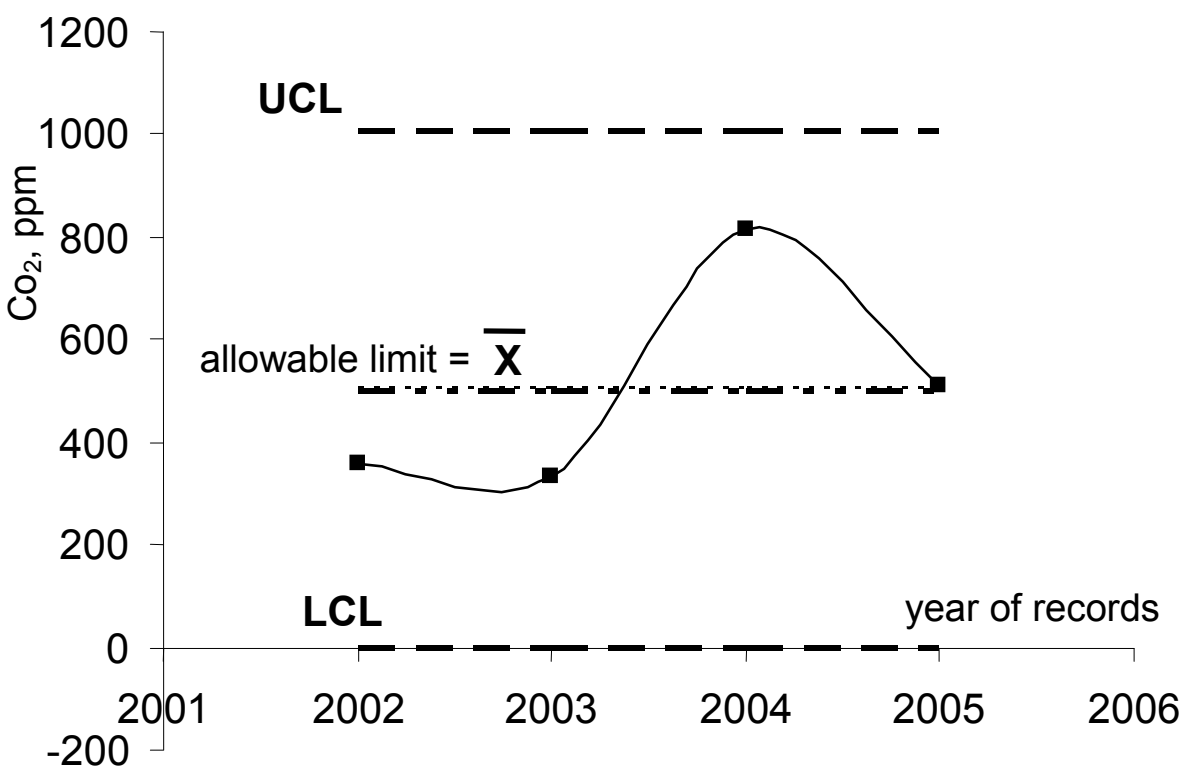

Fig.(7) $\mathrm{CO}_{2}$ Emission in the service center

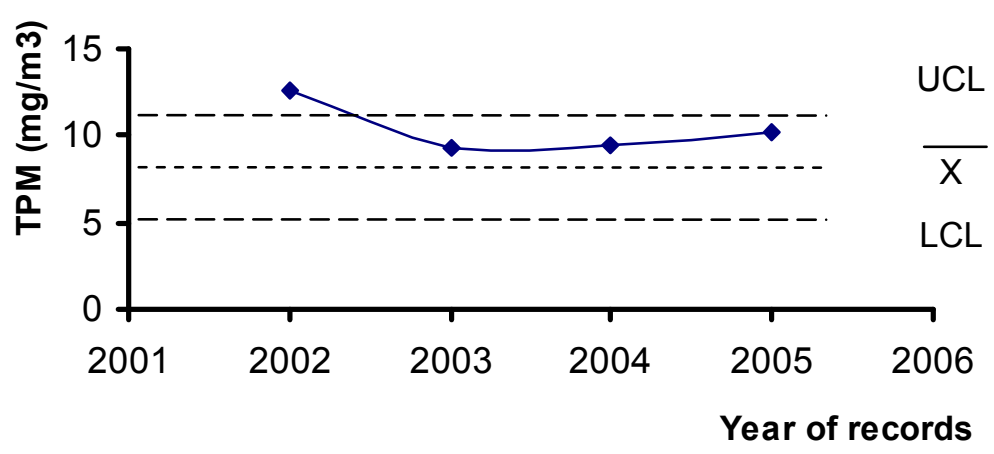

Fig.8 Concentration of TPM in furnaces region 


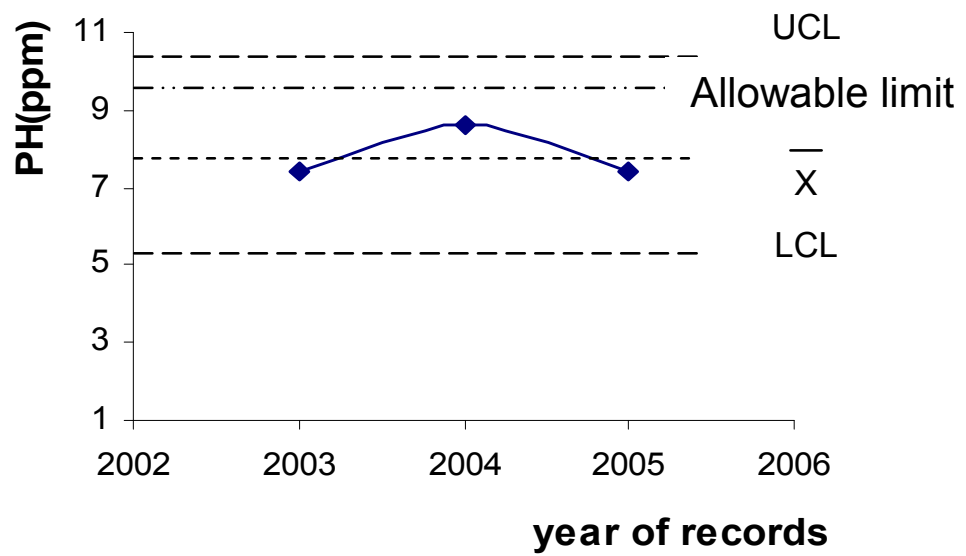

Fig.9 Concentration of $\mathrm{PH}$ in wastewater

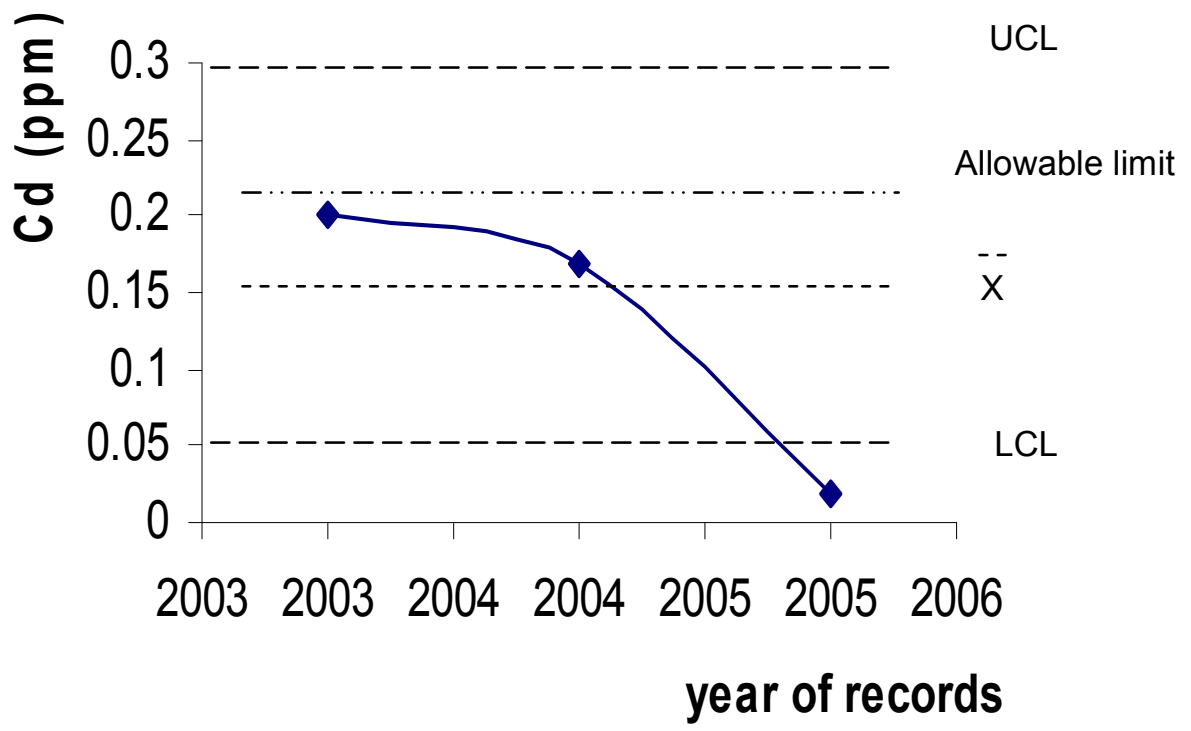

Fig.10 Concentration of $\mathrm{Cd}$ in wastewater 